\title{
Psicologia Evolucionista e a Seleção Sexual: O Caso da Linguagem
}

\author{
Fernando Orphão de Carvalho \\ Universidade de Brasília
}

\begin{abstract}
RESUMO - Na tentativa de entender o caráter adaptativo e a história evolucionária dos processos cognitivos subjacentes ao comportamento lingüístico, uma série de mecanismos e conceitos advindos da teoria evolucionária tem tido, recentemente, sua potencial relevância aferida em uma série de estudos, entre eles, o chamado "Efeito Baldwin" e a teoria da seleção inclusiva (Kin Selection Theory). No presente trabalho, é oferecida, além de uma breve revisão do conceito de seleção sexual e do seu uso e status na Psicologia Evolucionista, uma crítica de uma proposta particular acerca do papel que o processo de seleção sexual possa ter tido no desenvolvimento da capacidade de linguagem na linhagem do Homo sapiens sapiens. Além de pontos específicos à hipótese sujeita à análise, são levantados também problemas e questões de natureza mais ampla e relevante para pesquisas posteriores.
\end{abstract}

Palavras-chave: psicologia evolucionista; seleção sexual; diferenças sexuais; linguagem.

\section{Evolutionary Psychology and Sexual Selection: The Case of Language}

\begin{abstract}
Within the broader project that strives to understand the evolutionary history of the processes that brought about the emergence of the cognitive capacities underlying the linguistic behavior of our species, a number of concepts and theoretical accomplishments from evolutionary biology have been subject to scrutiny. Among them, the so-called "Baldwin Effect" and the theory of kin-selection have figured prominently. In the present study we will develop a short review about the concept of sexual selection, its use and status in Evolutionary Psychology, as well as a critical assessment of a particular hypothesis that calls on sexual selection to explain some features of the human language faculty. Besides the specific points regarding this hypothesis, some general issues and directions for future research will be discussed.
\end{abstract}

Key words: evolutionary psychology; sexual selection; sex differences; language.

Quais foram os eventos e forças evolucionárias cruciais para que a espécie humana desenvolvesse sua sofisticada capacidade de comunicação? Qual é a ligação entre essas capacidades e funções biológicas mais básicas como a escolha de parceiros ou a competição por acesso a recursos reprodutivos? À parte de fenômenos historicamente contingentes e pressões adaptativas particulares, como a emergência do bipedismo (Aiello, 1996), ou a seleção positiva para a formação de grupos maiores de indivíduos (Dunbar, 1993; van Schaik, 1982), alguns processos e contextos evolucionários mais gerais têm sido considerados relevantes para que respostas sejam dadas a essas questões: por exemplo, o "Efeito Baldwin" (Cf. Hinton \& Nowlan, 1987), que consiste na manutenção de pressões, durante várias gerações de uma população reprodutivamente ligada, com o efeito de que traços ou comportamentos aprendidos sejam "assimilados" ao genótipo e passem a se expressar em gerações seguintes sem a necessidade de pressões ambientais sobre o processo de desenvolvimento ontogenético (Waddington, 1942), já foi utilizado em modelos computacionais de evolução de comunicação em populações de agentes (Yamauchi, 2004) e foi colocado como uma linha fértil de pesquisa acerca do problema (Pinker \& Bloom, 1990)2 .

1 Endereço: Universidade de Brasília, Laboratório de Línguas Indígenas, Caixa Postal 4467, Brasília, Brasil 70910-900. E-mail: fernaoorphao@yahoo.com.br
Uma outra proposta (Fitch, 2004) envolve a idéia de que a comunicação vocal tenha sofrido elaborações substanciais em nossa linhagem de primatas devido à seleção por certas modificações adaptativas no contexto da interação entre indivíduos com "interesses genéticos em comum", como entre as fêmeas e seus filhotes. Tal hipótese envolve crucialmente a noção de "seleção inclusiva" (Bertram, 1976; Hamilton, 1964).

Nas seções seguintes analisaremos brevemente o conceito de seleção sexual e seu papel dentro do programa mais amplo da psicologia evolucionista. Posteriormente, uma abordagem específica a respeito do suposto papel que o processo de seleção sexual possa ter tido na evolução da faculdade humana da linguagem será examinada.

\section{Seleção Sexual}

Desde as sugestões pioneiras de Darwin encontradas em The Descent of Man (1871/1997), tem sido comum se diferenciar entre dois processos evolucionários não-estocásticos, que podem ser responsáveis pela fixação de alelos particulares em

2 Cabe notar que o processo de "assimilação" como definido por Waddington não implica na transmissão hereditária de caracteres adquiridos, como na hipótese já refutada atribuída a J.-B. Lamarck (citado por Dawkins, 1983). O termo recebe interpretação dentro de teorias mais claras acerca dos custos e benefícios envolvidos na adoção de "estratégias alternativas" de relação entre o processo de desenvolvimento de um indivíduo e certas classes de sinais ambientais (Komarova \& Nowak, 2001). 
uma população ou causar a evolução de complexos adaptativos: a seleção natural e a seleção sexual (Mayr, 1997). Enquanto o primeiro processo é tido como afetando a frequiência de genes e caracteres envolvidos na obtenção de recursos somáticos e implicados diretamente na viabilidade dos organismos, a seleção sexual estaria envolvida na evolução dos ditos "caracteres sexuais secundários", que cumprem uma função na escolha de parceiros reprodutivos ou na competição intrasexual por seu acesso (Chagnon, 1988; Clutton-Brock, 1983; Harvey \& Bradbury, 1993). A necessidade de se distinguir entre os dois tipos de processo já parecia justificada a Darwin: muitas vezes um caractere sexual secundário pode auxiliar um indivíduo na escolha e retenção de parceiros, mas pode igualmente implicar custos grandes para sua sobrevivência, por exemplo, em termos de investimento metabólico e nutricional adicional durante o desenvolvimento ou em termos de vulnerabilidade à predação (Grafen, 1990; Zahavi, 1975).

As pressões adaptativas implicadas pela necessidade de se encontrar e assegurar a presença de parceiros e acessos aos seus gametas, ou seja, os problemas aos quais os traços sexuais secundários funcionam como soluções, constituem-se basicamente na competição entre membros do mesmo sexo e na necessidade em se atrair membros do sexo oposto. O primeiro tipo de seleção é chamado de seleção intrassexual e o segundo de seleção intersexual (Clutton-Brock, 1983; Harvey \& Bradbury, 1993; Thornhill, 1986; Trivers, 1972). Da forma como a entendemos hoje, a teoria da seleção sexual compõe um corpo coerente, compreensivo, falsificável e altamente corroborado de hipóteses acerca da evolução de uma série de caracteres e da distribuição de caracteres (sejam eles fisiológicos ou comportamentais) em diversas populações (Cf., Houde, 2001).

A observação fundamental da teoria da seleção sexual é a de que machos e fêmeas diferem quanto ao investimento relativo alocado no processo de produção de gametas, reprodução e investimento na promoção do desenvolvimento da prole (Thornhill, 1986; Trivers, 1972; Williams, 1966) ${ }^{3}$.

Com relação à estrutura gamética, as fêmeas fazem um investimento maior do que os machos na manutenção de suas células altamente dispendiosas e dotadas de mecanismos metabólicos complexos, quando comparadas às células espermáticas (Bateman, 1948). De acordo com tal observação, as fêmeas (ou o sexo que faz o maior investimento reprodutivo) seriam uma espécie de "recurso limitador" para o potencial reprodutivo de uma população, que seria alvo de competição por acesso pelos indivíduos que fazem o menor investimento (normalmente, os machos; Trivers, 1972). Haveria, portanto uma seleção positiva por indivíduos capazes de competir pelo acesso aos gametas mais caros (seleção intrassexual) e por indivíduos que devem ser altamente discriminativos na sua escolha de parceiros, já que os custos maiores da reprodução serão pagos por eles mesmos (seleção intersexual). Os machos que menos investem na formação dos zigotos são menos discriminativos e têm um potencial reprodutivo maior, muito embora a taxa de variação

3 O investimento parental é definido como um conjunto de traços ou comportamentos de um indivíduo que promove um aumento na aptidão (fitness) de um membro de sua prole causando um decréscimo na aptidão do indivíduo que expressa tal comportamento ou traço (Trivers, 1972). Tal tipo de caractere se encaixa dentro da noção técnica de "comportamento altruísta" (Hamilton, 1964; Wilson, 1975). de sucesso reprodutivo entre os machos tende a ser maior do que entre as fêmeas. Isso implica que, grosso modo, os machos investem em estratégias de maximização da sua contribuição genética para gerações posteriores apostando nos números, enquanto as fêmeas investem na qualidade de sua cria, selecionando "bons genes", por meio de indicadores de aptidão, ou escolhendo parceiros com capacidade de investimento no desenvolvimento da cria (Alexander \& Borgia, 1979; Thornhill, 1986). A teoria da seleção sexual não requer que o baixo nível relativo de competição se correlacione positivamente com as fêmeas (que são, por definição, aquelas que possuem os gametas mais dispendiosos). Isso por que o investimento diferencial pode assumir outras formas: nos mamíferos, por exemplo, as fêmeas são ainda responsáveis pela amamentação e, entre diversos peixes e pássaros, a maioria dos cuidados direcionados aos recém-nascidos é encargo dos machos. A assimetria entre os investimentos relativos dos sexos para com o desenvolvimento das crias é freqüentemente chamada de "Razão Sexual Operacional" (Operational Sex Ratio - OSR; Cf. Emlen \& Oring, 1977) e é tradicionalmente compreendida como uma razão entre o número de indivíduos do sexo que faz o menor investimento e que estejam disponíveis para fertilização de cada indivíduo do sexo de maior investimento. Organizações sociais extremamente poligâmicas, como, por exemplo, a dos gorilas (Gorilla gorilla), possuem um OSR extremamente enviesado para o sexo masculino, o que implica também menor investimento paternal. O OSR é dito enviesado para um dos sexos particulares quando esse sexo é o locus proeminente de competição por acesso aos gametas do sexo oposto. Tal conceito implica a possibilidade de que o OSR pode se tornar enviesado para o sexo feminino em situações nas quais os machos contribuam com investimento ao desenvolvimento da prole e, portanto, tenham um comportamento mais discriminativo na escolha de parceiras. As fêmeas, nessa situação, desenvolveriam caracteres ornamentais como pistas para a escolha efetuada pelos machos. Como testemunha do enorme sucesso preditivo e explanatório da teoria da seleção sexual, tais situações foram observadas em diversas espécies existentes (Cf. Houde, 2001).

Embora o processo de seleção intrasexual seja mais bem compreendido e seus correlatos adaptativos bem mais conspícuos (garras, caninos, porte físico etc.), a questão da seleção intersexual (i.e., a seleção discriminativa por parte do sexo que efetua os maiores investimentos reprodutivos) tem atraído muito mais atenção. As questões levantadas por tal processo incluem: 1) como as fêmeas escolhem determinado traço fenotípico como sinal de "bons genes" ou de potencial de investimento na prole, 2) qual a interação dessas relações assimétricas entre os sexos para o processo de seleção sexual e 3) quais as conseqüências em termos da composição estatística de genótipo/fenótipos alternativos entre os indivíduos do sexo sujeito à seleção mais discriminativa (aquele de menor investimento parental).

Em busca de se responder algumas das perguntas elencadas acima, dois processos básicos têm sido reconhecidos como relevantes (e possivelmente complementares) para a compreensão da seleção intersexual: o Processo de Fisher (Fisher, 1930) e o Handicap de Zahavi (Zahavi, 1975).

$\mathrm{O}$ processo de Fisher descreve uma dinâmica evolucionária particular caracterizada pela co-evolução entre o 
comportamento de seleção das fêmeas e o traço particular do fenótipo dos machos usados como "pista" para a seleção das fêmeas. A idéia é a de que, havendo variação em termos de aptidão (fitness) entre os machos de uma população e havendo igualmente uma variação entre as fêmeas, no que diz respeito ao seu comportamento de escolha de parceiros, aquele grupo de fêmeas que escolhe como parceiros os mais aptos também experimentará um regime de seleção positiva. Segue então que ambos os traços (ornamentos masculinos e preferências femininas) sofrerão um aumento de sua frequiência relativa na população. Menos óbvio, mas de crucial importância para o processo de Fisher, é que o processo de escolha das fêmeas tem os efeitos de um processo de seleção direcional sobre os caracteres masculinos, em que os valores médios de um traço (e.g., tamanho da cauda de um pássaro) são, a cada geração, elevados, caso haja a ação seletiva das fêmeas que escolhem os maiores valores associados a um traço qualquer. Mesmo que os filhos dessas fêmeas não estejam mais sujeitos à pressão seletiva positiva a que seus ancestrais machos estavam (por que as pressões ecológicas anteriormente ativas sobre os traços fenotípicos usados como pistas pelas fêmeas foram suspensas, por exemplo), eles, mesmo assim, experimentarão uma vantagem no que diz respeito às suas taxas de replicação por que os comportamentos de discriminação das fêmeas também são herdados e tornam-se relativamente mais comuns sob o regime de seleção positiva.

O Processo de Fisher foi reformulado de maneiras alternativas, com o intuito de se verificar os efeitos de suposições distintas, por exemplo, acerca dos tipos de caracteres em questão e do seu padrão de transmissão (Cf., e.g., Kirkpatrick, 1982; O`Donald, 1980, 1983). Um dos problemas apontados no modelo original de Fisher (1930) é que, embora a possibilidade de evolução do caractere de preferência das fêmeas tenha sido demonstrada, havia ainda um non sequitur ou uma "suposição não-trivial" no raciocínio de Fisher: por que as fêmeas escolheriam, a cada geração, os indivíduos com desenvolvimentos extremos de seus caracteres? ${ }^{4}$

Como tentativa de responder essa questão, Amotz Zahavi (1975) propôs a seguinte hipótese: os caracteres extremos apresentados por machos de diversas espécies (e.g., caudas longas, chifres grandes e desenvolvidos ou plumagens densas e coloridas) impõem ao indivíduo uma série de custos à sua aptidão: custos relativos à alocação de recursos durante o desenvolvimento, manutenção metabólica e nutricional extra requerida pelo caractere, exposição maior à predação etc. Logo, tais caracteres funcionariam como sinais honestos da "qualidade genética" do indivíduo, pois apenas indivíduos aptos o suficiente poderiam compensar os efeitos negativos sobre a viabilidade e sobrevivência impostos pela presença do caractere em questão. A idéia central é a de que a freqüiente oposição entre seleção natural e seleção sexual, evidenciada por caracteres epigâmicos (i.e., caracteres sexuais secundários) que afetam a viabilidade de um indivíduo ao mesmo tempo em que aumentam sua fertilidade ou seu sucesso reprodutivo, não é um efeito acidental da dinâmica evolucionária, mas uma condição central para o funcionamento da seleção sexual (Zahavi, 1975).

4 Na realidade algumas outras imperfeições e "pressupostos implícitos" do modelo de Fisher foram revelados por trabalhos posteriores de formalização e incorporação de maior detalhe acerca das bases genéticas dos caracteres envolvidos (O`Donald, 1983).
Alguns outros detalhes e questões residuais acerca dos mecanismos de seleção sexual serão considerados durante a discussão do papel da teoria na Psicologia Evolucionista e de uma proposta particular acerca da evolução da linguagem.

\section{Seleção Sexual e a Psicologia Evolucionista}

A grande maioria das pesquisas em Psicologia Evolucionista tem se debruçado sobre a construção e o teste de hipóteses acerca de diferentes mecanismos psicológicos e fisiológicos possuídos por machos e fêmeas, mecanismos estes usados em funções adaptativas distintas como a escolha e retenção de parceiros ou a alocação de cuidados à prole (Buss \& Haselton 2005; Buss, 1995; Hill \& Reeve, 2004; Symons, 1979).

As hipóteses são formuladas de acordo com dois tipos de hipóteses auxiliares: 1) acerca dos tipos de pressões adaptativas confrontadas por populações humanas ancestrais e que tenham, portanto, promovido a elaboração de caracteres com consequiências adaptativas sob tais circunstâncias e 2) a partir do aparato geral da teoria da seleção sexual, além, é claro, de resultados teóricos, generalizações e mecanismos mais gerais providos pela teoria evolucionária (Buss, 1995; Durrant \& Ellis, 2003; Tooby \& Cosmides, 1990).

No campo da psicologia evolucionista humana, foi proposta uma hipótese acerca das distintas estratégias de escolha de parceiros utilizadas por membros de cada sexo. Um dos fatos que particularizam as relações reprodutivas na nossa espécie é o fato de as fêmeas não darem demonstrações óbvias de estarem no seu período fértil. Em outras espécies de primatas, como os chimpanzés (Pan troglodytes), a apresentação de tais sinais é fisiologicamente inevitável e funciona como pista para que os machos que retém o controle ao acesso às fêmeas entrem em um "estado de alerta", no que diz respeito a possíveis infidelidades por parte de suas parceiras (para o relato de observações naturalísticas desse tipo de comportamento, ver de Waal, 1996).

Isso porque os machos não teriam a certeza de que eles foram os únicos indivíduos a manterem relações sexuais com determinada fêmea durante seu período fértil, levantando a possibilidade de que eles venham a investir na criação de um indivíduo com o qual eles tenham um grau de parentesco nulo. Mais precisamente, um gene "altruísta" que contribua para um investimento paternal significativo poderia não atingir fixação em uma população, pela não satisfação da inequação de Hamilton, i.e., o gene não promoveria um aumento diferencial na sua representatividade em gerações seguintes da população, por não ter os custos advindos do comportamento de investimento contrabalanceados pelos benefícios de se ter, como beneficiário do investimento, um indivíduo geneticamente relacionado

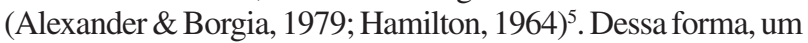
macho que investisse recursos no desenvolvimento e promoção da sobrevivência da prole de uma fêmea, e se esta foi fecundada por um outro macho geneticamente não relacionado ao primeiro, estaria incorrendo nos custos, mas não nos benefícios, da alo-

5 A inequação de Hamilton é usualmente tida como uma condição para a evolução de comportamentos 'altruístas'. Ela define que os custos (C) para o indivíduo que expressa o comportamento deve ser menor do que o benefício (B) para o recipiente da ação diluído pelo coeficiente de parentesco (r) entre ambos: Br>C. Para maiores detalhes, ver Grafen (1992). 
cação de investimento (Hrdy, 1981; Thornhill, 1986; Trivers, 1972). Por outro lado, um macho que haja de forma "egoísta", fecundando inúmeras fêmeas que recebem o investimento de outros machos, estaria em enorme vantagem.

Tais observações atentam para o fato de que as condições para a evolução de genes que favoreçam comportamentos altruístas são bastante delicadas e que, em espécies com fertilização interna com certo grau de poliginia e nas quais não existam pistas óbvias acerca dos ciclos de ovulação das fêmeas, há fortes pressões seletivas por machos que expressem estratégias efetivas de "certificação de paternidade", de modo a evitar o investimento inócuo de recursos paternais.

A necessidade de tais recursos faz-se ainda mais forte em espécies em que as fêmeas dão à luz a filhotes extremamente imaturos e dependentes (expensive offspring) e assim teriam de obter meios de "barganhar" com machos a maior quantidade possível de recursos investidos (Foley, 1996; Hawkes, O'Connell, Blurton Jones, Alvarez \& Charnov, 1998). Tal observação não implica, obviamente, que a provisão das crias não esteja dentro dos "interesses genéticos" dos machos, i.e., que o processo de seleção não possa, em regra, promover a evolução de machos que expressem tais comportamentos. Cabe lembrar, no entanto, que o investimento paternal é muitas vezes contingente à certeza de paternidade e que o potencial reprodutivo dos machos é maior que o das fêmeas (em termos de investimento na produção de gametas). O investimento maternal direcionado, por exemplo, à proteção e nutrição de uma prole ou mesmo em um único indivíduo, pode comprometer a fertilidade ou o potencial de investimento posterior por parte da fêmea, sendo esse fator o "feedback negativo" atuante sobre as fêmeas incapazes de amenizar seu investimento pelo investimento conjunto alocado por um parceiro (Clutton-Brock, 1983; Trivers, 1974). Situações como essa se encaixam na noção mais ampla de "conflito evolucionário", no qual indivíduos que compartilham de interesses em comum (e.g., promoção da sobrevivência da prole) podem ter como estratégia ótima de ação um comportamento, caractere ou disposição fisiológica distinta da estratégia ótima do outro indivíduo envolvido (Haig, 1993; Trivers, 1974).

Partindo dessa "metateoria" evolucionária (Cf. Durrant \& Ellis, 2003) e de alguns fatos particulares acerca da fisiologia reprodutiva humana, uma série de hipóteses acerca de diferenças intersexuais em termos de adaptações psicológicas foram propostas e empiricamente corroboradas em uma série de estudos. Com respeito a emoções, como o ciúme, por exemplo, a hipótese mais aceita entre psicólogos evolucionistas é a de que homens, mais do que mulheres, tornam-se ciumentos a partir de pistas ou evidências de traição de cunho sexual, por promover a incerteza de paternidade, e as mulheres, mais do que os homens, tornar-se-iam ciumentas ao notar evidências de traição emocional, o que constituiria um potencial indicador de extravio de recursos e investimentos para uma outra fêmea (Buss \& Haselton, 2005; Buss, Shackelford, Choe, Buunk \& Dijkstra, 2000). Sob essa perspectiva, emoções e outras reações fisiológicas e comportamentais, tipicamente consideradas como "destrutivas" ou mesmo patologizadas, podem ser vistas como mecanismos psicológicos adaptativos (Cf. Nesse \& Williams, 1996; Sloman, Chrisley \& Scheutz, 2005).

Outra hipótese notória desenvolvida por psicólogos evolucionistas diz respeito às diferenças sexuais quanto aos critérios de escolha de parceiros (Buss, 1989; Kenrick \& Keefe, 1992). Tendo em vista o que foi dito nas seções anteriores, as hipóteses derivadas (e empiricamente corroboradas em estudos trans-culturais, como Buss, 1989), são as de que as mulheres possuiriam adaptações psicológicas, motivacionais, que as tornariam sensíveis a demonstrações de status nos homens como sinal da capacidade de investimento, por exemplo, de recursos materiais, como alimentos, para a provisão de suas crias. Os homens, por outro lado, teriam desenvolvido preferências por mulheres mais jovens como parceiras reprodutivas. As razões seriam: 1) a de que mulheres mais jovens teriam um potencial reprodutivo maior, por estarem mais distantes do fim de sua idade reprodutiva (onset da menopausa) do que mulheres mais velhas e 2) mulheres mais jovens seriam igualmente mais férteis, i.e., teriam uma probabilidade maior de engravidar. Alguns dos traços fenotípicos que seriam sinais das qualidades desejadas seriam: lábios cheios, pele lisa, bom tônus muscular, além de certas distribuições "ótimas" de gordura corporal ${ }^{6}$.

\section{A Linguagem e a Seleção Sexual}

Em primeira instância, a idéia de que o processo de seleção sexual possa ter contribuído para o desenvolvimento de faculdades cognitivas, motoras e perceptuais adaptadas para o comportamento lingüístico pode parecer mal formulada, dado que tal processo restringe-se à elaboração gradativa de caracteres sexuais secundários, i.e., traços fisiológicos, morfológicos e comportamentais envolvidos no processo de seleção e retenção de parceiros reprodutivos (Darwin, 1871/1997; Miller, 1998; Thornhill, 1986). Entretanto, um dos pressupostos norteadores da teoria da seleção sexual é a de que, possivelmente, esta possa prover explicações "últimas" (Mayr, 1961) para todas as diferenças sexuais observadas (Arnold, 1983; Clutton-Brock, 1983; Trivers, 1972; Thornhill, 1986).

A evidência comparativa advinda de sociedades de caça e coleta, bastante utilizada na psicologia evolucionista (Marlowe, 2005), não parece nos fornecer suporte para um papel óbvio da seleção sexual em relação à linguagem (Chagnon, 1988; Fitch, 2004; Kaplan \& Hill, 1985; Smith, 2004). A competição intrasexual entre machos parece estar crucialmente relacionada à caça, guerra, interações agonísticas e violência, e não à variação em efusão e virtuosismo verbal entre indivíduos, como é incidentalmente sugerido (Miller, 2002; Pinker \& Bloom, 1990).

Igualmente recalcitrantes são as inferências a partir de algumas conhecidas diferenças sexuais em medidas verbais experimentais, como tempos de reação em tarefas de acesso lexical ou a suposta preferência feminina pelo acesso direto de estruturas complexas (e.g., palavras compostas de raízes acrescidas de prefixos ou sufixos) que seriam compostas on line, mediante regras, por homens (Estabrooke, Mordecai, Maki \&

6 O caráter "honesto" da espessura labial como indicador das propriedades relevantes (e.g., fertilidade) deve-se ao afinamento dos lábios com o avanço da idade. No caso de uma preferência por lábios mais grossos ser herdada, um gene que promovesse a expressão de tal preferência seria selecionado preferencialmente a genes que contribuam para escolhas de parceiros menos férteis. A distribuição de gordura corporal está ligada de maneira mais complexa às taxas de estrogênio da puberdade (Buss, 1999). 
Ullman, 2002; Kimura, 1999; Maki, Zonderman \& Resnick, 2001). O fato é que existe uma forte possibilidade de que tais efeitos possam ser correlatos seletivamente neutros dos níveis de estrogênio. Tal situação não é absolutamente sem precedentes, sendo o caso clássico o do pseudo-pênis da Hiena-Pintada (Crocuta crocuta) que, apesar de usados em uma série de comportamentos sociais desses animais, são muito provavelmente um concomitante dos altos níveis de androgênio presentes nas fêmeas dessa espécie (Gould \& Vrba, 1982).

Um exemplo clássico de um traço anatômico relacionado à produção de linguagem e que muito provavelmente evoluiu por meio de seleção sexual é o posicionamento da laringe nos machos de nossa espécie. Em todos os indivíduos, a partir de cerca de 3 a 4 meses de idade, há um processo de descimento da laringe para a posição que a mesma ocupa nos adultos, aproximadamente na altura da 5ํㅡㄹ vértebra cervical (Lieberman, 1984). O descimento da laringe é tido por muitos como um resultado adaptativo de pressões por um trato articulatório capaz não só de produzir uma gama maior de gestos, mas também de prover um espaço mais amplo onde modificações acusticamente robustas do espectro sonoro provido pela fonte laríngea podem ser efetuadas (Lieberman \& Crelin, 1971; Stevens, 1972). Entretanto, nos machos de nossa espécie, há um descimento adicional e significativo da laringe sob a influência de androgênios durante o onset da puberdade (Fitch \& Giedd, 1999; Hollien, Green \& Massey, 1994). O descimento adicional da laringe, observado nos machos, teria um efeito acústico bastante claro: com o aumento do comprimento do tubo de ressonância formado pela cavidade orofaríngea, há uma diminuição da frequiência média dos formantes, além da redução das distâncias entre os formantes, i.e., um menor coeficiente de "dispersão dos formantes", definido pela média das distâncias (em Hz) entre formantes adjacentes (Fant, 1960; Fitch, 1997; Riede \& Fitch, 1999). Esse caso de dimorfismo morfológico no aparelho fonador e articulatório tem sido interpretado como resultado de um processo de seleção sexual, muito embora haja dúvida acerca de se tratar de um caractere usado como sinal "honesto" de viabilidade ou fertilidade (Hughes, Harrison, \& Gallup, 2002) ou se o padrão teria evoluído pela competição entre machos como uma marca de dominância (Ohala, 1984, 2000; Puts, Gaulin \& Verdolini, 2006), muito embora esses processos não sejam mutuamente exclusivos (Halliday, 1983) ${ }^{7}$.

Após esse preâmbulo, consideraremos, em maior detalhe e de forma crítica, uma hipótese avançada na literatura acerca da possível influência da seleção sexual na evolução da faculdade humana da linguagem.

\section{A hipótese de Okanoya}

O psicólogo Kazuo Okanoya (2004) propôs que o processo de seleção sexual, mediante a idéia do Handicap de Zahavi, pode ter sido o mecanismo responsável pela evolução de parte da faculdade humana da linguagem, em especial, a

$7 \quad$ Neste ponto é relevante observar que alguns estudos desta natureza (van Dommelen \& Moxness, 1995) sofrem de certas deficiências por não controlar certas variáveis relevantes, como a flutuação dos níveis circulantes de esteróides em função do ciclo menstrual feminino, que tem efeitos demonstrados sobre certas medidas dependentes (Hughes \& cols., 2002; Wadnerkar, Cowell \& Whiteside, 2006). organização hierárquica sintática das línguas naturais. Okanoya (2002) desenvolveu um estudo acerca das diferenças entre a complexidade dos sistemas "sintáticos" utilizados por pássaros canoros de duas variedades, uma doméstica e outra selvagem, de uma espécie particular de ave, Lonchura striata (var. domestica) e Lonchura striata, respectivamente. A hipótese desenvolvida pelo autor assenta-se sobre os seguintes achados: a variedade domesticada dessa espécie apresenta um repertório de canções mais complexas do que o da variedade selvagem, muito embora a seleção artificial efetuada sobre a variedade teve o propósito de desenvolver apenas o valor médio de um caractere, a plumagem. Okanoya identificou, ainda, os mecanismos neurais por trás do controle motor envolvido na produção das canções em ambas as variantes e mostrou que, enquanto a variedade doméstica é capaz de aprender ambos os padrões de organização da canção das duas espécies, a espécie selvagem é incapaz de aprender e executar as canções mais complexas da variedade domesticada. De especial importância para o processo de seleção sexual, as fêmeas de ambas as variedades mostraram uma preferência pelos padrões mais complexos de organização das canções.

O trabalho elegante de Okanoya culmina com a seguinte hipótese evolucionária: a domesticação dos pássaros acentuou o processo de seleção sexual e levou ao desenvolvimento de traços extremos nos machos: não só a plumagem como também um sistema mais complexo de comunicação. Especialmente no que diz respeito a essa segunda característica, algumas analogias ou extrapolações para o caso da evolução da linguagem seriam possíveis.

No que diz respeito à linguagem, o autor parte do fato de que algumas características do sistema sintático das línguas naturais, como a organização hierárquica e a recursividade do processo de formação/reconhecimento de sentenças, têm sido o foco de discussões acaloradas entre dois grupos de pesquisadores: aqueles que assumem uma história evolutiva "previsível" para a evolução da linguagem (i.e., pela qual, como com qualquer caractere demonstrando complexidade adaptativa, o processo de seleção natural, operando de maneira gradual sobre variantes mínimos e viáveis, produz um complexo design funcional, Cf. Dawkins, 1983; Pinker \& Bloom, 1990) e outros que, não encontrando motivações funcionais óbvias para a existência de determinadas características, defendem que a ação (possivelmente, não-adaptativa) de "restrições de desenvolvimento" ou "princípios gerais de organização" possa explicar os padrões observados (Newmeyer, 1998; Uriagereka, 2000).

Okanoya (2004) vê então no processo de seleção sexual, e em especial na idéia de handicap, um meio potencial de explicar a evolução da sintaxe das línguas naturais humanas:

\footnotetext{
Sexual selection is assumed to be a driving force for language evolution by several authors (Miller, 2000), but Okanoya (2002) specifically pointed out that it is the syntactical domain rather than that of semantics in which sexual selection is strongly related with language, because sexual selection could help evolution of arbitrary complex traits (p. 210).
}

O problema inicial com a hipótese de Okanoya está flagrante já na citação acima: a própria idéia de um princípio explanatório que explique toda e qualquer coisa é em si um oxímoro. $\mathrm{O}$ conceito de uma explicação em qualquer ciência 
empírica pressupõe uma noção básica de exclusão de possibilidades: levantar uma hipótese acerca de um fator causal, explanatório, que é compatível com qualquer evidência possível equivale a se apelar para hipóteses empiricamente vazias, não-falseáveis (Popper, 1959).

Mesmo que deixemos questões epistemológicas gerais de lado e nos concentremos na explicação particular que queremos, existem outros problemas. Em primeiro lugar, não queremos simplesmente um processo evolucionário que explique a evolução de um traço de complexidade arbitrária. O que se deseja são processos que expliquem os padrões populacionais ou comparativos observados, dadas as condições e restrições filogenéticas particulares do processo de evolução dos hominídeos (e.g., aquelas experimentadas por caçadores-coletores do Pleistoceno) e da dinâmica inferida de modelos acerca de outras pressões adaptativas e também acerca de variáveis do contexto ecológico da evolução humana que são crucialmente relevantes para se entender o funcionamento da seleção sexual (Arnqvist 2006; Miller \& Todd, 1995). Partindo dessas qualificações, observa-se um ponto em que a analogia entre os pássaros e Homo sapiens parece logo se diluir. Na história dos hominídeos, observou-se não uma acentuação mas uma atenuação do padrão de dimorfismo corporal observado em populações em que há extrema competição entre os machos (McHenry, 1994; McHenry \& Coffing, 2000). Tal situação contrasta diametralmente com aquela observada nas populações sujeitas à seleção artificial do estudo de Okanoya. Como acontece em diversos mamíferos, os machos passaram a investir parte de seus recursos no desenvolvimento de traços morfológicos e fisiológicos envolvidos em um tipo peculiar de competição por acesso aos gametas das fêmeas, a competição espermática (Baker \& Bellis, 1995; Gallup \& Burch, 2004) ${ }^{8}$.

Em adição a tais considerações, a existência de um investimento paternal acentuado em nossa espécie introduz elementos, no jogo da seleção sexual, ausentes de diversas espécies que possam ser tomadas como exemplares: a existência de investimento paternal além daquele incluído na formação de gametas inicia um processo de seleção por machos também mais discriminativos. Mesmo que espécies de aves nas quais haja certo grau de monogamia e investimento paternal sejam tomadas como modelo, existem ainda os fatores da lactação e da gestação nos mamíferos (o que acentua o investimento por parte das fêmeas) e, portanto, cria também uma seleção por fêmeas que "procurem" não só sinais de viabilidade como também de capacidade de investimento (Trivers, 1972; Symons, 1979). Nesse sentido, não parece claro se Okanoya pretende que o critério de seleção de parceiros esteja baseado no reconhecimento de traços de viabilidade ou traços que atestem a capacidade de investimento por parte do macho (Miller, 1998). Tal distinção, além de crucial dentro do maquinário da teoria da seleção sexual, nos parece igualmente importante para se estabelecer em que sentido um sistema sintático possuindo características como

8 O exemplo é relevante dado o corpo de evidências demonstrando a existência de "trade-offs" na alocação de recursos no desenvolvimento e manutenção de caracteres distintos, de acordo com as pressões seletivas atuantes na população e certos critérios de otimização (Simmons \& Emlen, 2006). Dessa maneira, o investimento em uma estratégia particular (comportamento, traço morfológico, etc.) impediria necessariamente um investimento de magnitude similar em uma estratégia alternativa. recursividade hierárquica seria indicador honesto de qualquer uma dessas propriedades, já que os custos de sinalização para a aplicação do Handicap de Zahavi devem ir além dos requisitos fisiológicos mínimos e inevitáveis para expressão dos caracteres. Nesse caso, por exemplo, um custo adicional além do suposto volume neural envolvido nos traços de memória de canções mais complexas nos pássaros (Fitch, 2004).

Um segundo problema, e que talvez seja mais grave sob o ponto de vista da teoria evolucionária, é o de que Okanoya deveria estar falando de populações e não de traços ou características in astratto. A dinâmica de populações é o cenário dentro do qual se desenvolvem fenômenos evolucionários. Somente por indiferença a essa observação fundamental poderíamos afirmar, como faz Okanoya, que o processo de seleção sexual pode levar ao desenvolvimento de "traços de complexidade arbitrária". Como já vimos, o processo de seleção intersexual poderia levar ao desenvolvimento de caracteres extremos nos machos se tanto estes quanto os caracteres de escolha das fêmeas forem herdados e que haja uma assimetria inicial, por exemplo, uma vantagem adaptativa para os variantes mais extremos dos caracteres masculinos presentes na população em um dado momento (iniciando o processo de co-evolução ou Processo de Fisher). Mas, para que tal situação ocorra, é preciso que, a cada geração, as fêmeas tenham um meio (uma motivação adaptativa e, portanto, não arbitrária) para ter uma preferência pelos machos com caracteres extremos, em relação à média da população de machos em uma distribuição normal. Nesse ponto entra o Handicap de Zahavi. A idéia de que o processo de seleção sexual pode levar ao desenvolvimento de traços arbitrariamente complexos equivale, em termos da dinâmica simples do processo de seleção, à manutenção interminável da seleção direcional por aqueles machos que possuam os caracteres mais desenvolvidos em cada "turno" da escolha de parceiros reprodutivos. Tal situação é implausível devido aos custos de viabilidade implicados por esses caracteres: como sinais "honestos" da viabilidade dos machos, os caracteres impõem custos a esses indivíduos, tornando-os, por exemplo, mais vulneráveis à predação e à ação de agentes patogênicos ou impondo custos relativos ao desenvolvimento (Kacelnik \& Norris, 1998). A seleção sexual só pode operar desse modo, desenvolvendo esses caracteres quando os custos de viabilidade não superam os ganhos em acesso e retenção de indivíduos do sexo oposto (Fisher, 1930; Zahavi, 1975). Se a média da população de machos passa a sofrer um "feedback negativo" grande devido aos custos de viabilidade, a seleção contra a média pode ser intensa o suficiente para levar a população à extinção (Harvey \& Bradbury, 1993) ou a população pode evoluir para um estado de polimorfismo estável, uma distribuição de valores dos caracteres dos machos na qual a média está apenas "gentilmente" desviada com relação aos valores ótimos de viabilidade "ecológica" dos machos (Maynard Smith \& Brown, 1986). Como as variáveis relevantes aqui são as freqüências relativas de certos valores para os traços de sinalização dos machos e sua relação com os componentes de viabilidade da adaptabilidade, as mesmas observações aplicam-se ao processo de seleção intrassexual (Harvey \& Bradbury, 1993).

A observação acerca de polimorfismos estáveis leva em consideração um fato ignorado no modelo de Okanoya e que merece maior atenção: a evolução de caracteres arbitrários seria impossibilitada também pelo fato de que há, em 
inúmeros casos, seleção dependente-de-freqüência quanto aos componentes de adaptabilidade dos machos relativos à retenção e acesso às fêmeas, também chamado, nesse caso, de efeito do macho raro (O’Donald, 1978, 1980). O polimorfismo estável é mantido, pois apenas quando o caractere favorecido pela escolha das fêmeas aparece em freqüências baixas na população é que as vantagens reprodutivas são significativas, mas nenhum dos variantes é definitivamente eliminado da população. Esse "teto" no valor máximo de adaptabilidade (i.e., de ganhos advindos do investimento de recursos no desenvolvimento de um caractere) estabelece um limite bastante direto para o desenvolvimento de um traço fenotípico.

As observações presentes nesta seção, acerca de uma hipótese particular sobre um fator causal relevante para se compreender a evolução da linguagem, têm um único objetivo: apontar para o fato de que os padrões de rigor no desenvolvimento de hipóteses evolucionárias expresso em outras áreas da psicologia evolucionista não parecem estar sendo seguidos no estudo da linguagem humana. A hipótese de Kazuo Okanoya baseia-se tão somente em uma analogia entre a comunicação de certas espécies de pássaros e a comunicação humana, não levando em conta um conhecimento mais pormenorizado de princípios evolucionários gerais e tampouco propondo hipóteses testáveis.

\section{Discussão e Conclusão}

O estudo moderno das línguas naturais, em especial a partir da "revolução Chomskyana" (Pinker, 1994), logrou êxito em integrar-se com o estudo explanatório, cientifico, mais amplo da cognição, cumprindo em grande parte os objetivos originais de formar uma ciência natural da linguagem (Chomsky, 2001; Kukla, 2001).

Embora a mudança epistemológica mais ampla tenha sido sensível, em termos das questões abordadas, a moderna ciência da linguagem continua insulada em relação às disciplinas biológicas tradicionais. Temas como variação interindividual, diferenças sexuais, ontogênese e, no que tange diretamente ao presente ensaio, caracterização evolucionária têm permanecido alheios à maioria dos lingüistas. Embora parte dessa situação deva-se a simplificações e idealizações metodológicas imprescindíveis (Chomsky, 2001), o presente estado do conhecimento já nos permite inúmeras vezes abrir mão ou ao menos "impor qualificações" a diversas das teses e construtos assumidos nas etapas incipientes do desenvolvimento da lingüística e das ciências cognitivas (Quartz \& Sejnowski, 1997).

No tocante às questões discutidas neste artigo, em especial no que diz respeito à nossa crítica da hipótese de Kazuo Okanoya, torna-se evidente a demanda por estudos que contemplem, por exemplo, diferenças lingüísticas individuais, diferenças sexuais, estimativas de herdabilidade $\left(h^{2}\right)$ de traços morfofisiológicos associados ao comportamento e cognição lingüísticas (ou de medidas experimentais padronizadas), além de padrões atípicos de desenvolvimento de linguagem. Os poucos estudos já realizados acerca desses temas são desconhecidos da maioria dos lingüistas teóricos ou não possuem nenhum vínculo maior com o estudo científico da estrutura da linguagem (Day, 1979), o que, portanto, explica em parte o desinteresse por parte dos lingüistas. Um grande esforço tem sido direcionado ao estabelecimento de "pontes" entre a teoria lingüística e campos como a neurociência, neuropsicologia e mesmo a genética comportamental (Phillips, Kazanina \& Abada, 2005; Stromswold, 2001). Dada a combinação desse tipo de aproximação e o crescente apelo de abordagens evolucionárias dentro da psicologia e das ciências cognitivas (Buss, 1999; Durrant \& Ellis, 2003; Pinker \& Bloom, 1990), o prognóstico de estudos que convirjam na compreensão de fenômenos cuja natureza é essencial para a caracterização biológica da linguagem nos parece justificadamente otimista.

\section{Referências}

Aiello, L. (1996). Terrestriality, Bipedalism and the Origin of Language. Em W. Runciman, J. Maynard Smith \& R. Dunbar (Orgs.), Evolution of Social Behaviour Patterns in Primates and Man (pp.269-289). Oxford University Press.

Alexander, R. \& Borgia, G. (1979). On the Origins and Basis of the Male-Female Phenomenon Em M. Blum \& N. Blum (Orgs.), Sexual Selection and Reproductive Competition in Insects (pp.417-440). Academic Press.

Arnold, S. (1983). Sexual Selection: the Interface of Theory with Empiricism. Em P. Bateson, (Org.), Mate Choice (pp.67-107). Cambridge: Cambridge University Press.

Arnqvist, G (2006). Sensory Exploitation and Sexual Conflict. Philosophical Transactions of the Royal Society B, 361, 375-386.

Baker, R. \& Bellis, M. (1995). Human Sperm Competition: Copulation, Masturbation and Infidelity. London: Chapman and Hall.

Bateman, A. (1948). Intra-sexual Selection in Drosophila. Heredity, 2, 349-368.

Bertram, B. (1976). Kin Selection in Lions and in Evolution. Em P. Bateson \& R. Hinde (Orgs.), Growing Points in Ethology (pp. 281-301). Cambridge: Cambridge University Press.

Buss, D. (1989). Sex Differences in Human Mate Preferences: Evolutionary Hypotheses Tested in 37 Cultures. Behavioral and Brain Sciences, 12, 1-49.

Buss, D. (1995). Psychological Sex Differences: Origins Trough Sexual Selecton. American Psychologist, 50(3), 164-168.

Buss, D. (1999). Evolutionary Psychology: The New Science of the Mind. Boston: Allyn and Bacon.

Buss, D. M., Shackelford, T. K., Choe, J., Buunk, B., Dijkstra, P. (2000). Distress about rivals: Reactions to intrasexual competitors in Korea, the Netherlands, and America. Personal Relationships, 7, 235-243.

Buss, D. \& Haselton, M. (2005). The Evolution of Jealousy Trends in Cognitive Science, 9, 506-506.

Chagnon, N. (1988). Life Histories, Blood Revenge and Warfare in a Tribal Population. Science 239, 985-992.

Chomsky, N. (2001). New Horizons in the Study of Language and Mind. Cambridge: University Press.

Clutton-Brock, T. (1983). Selection in Relation to Sex. Em D. S. Bendall (Org.), Evolution from Molecules to Men (pp.457-481). Cambridge: Cambridge University Press.

Darwin, C. (1997). The Descent of Man. Amherst: Prometheus Books. (Trabalho original publicado em 1871)

Dawkins, R. (1983). Universal Darwinism. Em D. S. Bendall (Org.), Evolution from Molecules to Men (pp.403-425). Cambridge: Cambridge University Press. 


\section{F. O. Carvalho}

Day, R. (1979). Verbal Fluency and the Language-Bound Effect. Em C. Fillmore, D. Kempler \& W. Wang (Orgs.), Individual Differences in Language Ability and Language Behavior (pp.5784). New York: Academic Press.

de Waal, F. (1996). Good Natured: the Origins of Right and Wrong in Humans and Other Animals. Harvard: University Press.

Dunbar, R. (1993). Coevolution of Neocortical Size, Group Size and Language in Humans. Behavioral and Brain Sciences, 16, 681-735.

Durrant, R. \& Ellis, B. (2003). Evolutionary Psychology. Em M. Gallagher \& R. Nelson (eds.), Comprehensive Handbook of Psychology, Vol. III, Biological Psychology (pp.1-35). New York: Wiley \& Sons.

Emlen, S. \& Oring, L. (1977). Ecology, Sexual Selection and the Evolution of Mating Systems. Science, 197, 215-223.

Estabrooke, I., Mordecai, K., Maki, P. \& Ullman, M. (2002). Effects of Sex Hormones on Language Processing. Brain and Language, 83, 143-146.

Fant, G. (1960). Acoustic Theory of Speech Production. The Hague: Mouton.

Fisher, R. (1930). The Genetical Theory of Natural Selection. Oxford: University Press.

Fitch, T. (1997). Vocal Tract Length and Formant Frequency Dispersion Correlate with Body Size in Rhesus Macaques. Journal of Acoustical Society of America, 102, 1213-1222.

Fitch, T. (2004). Kin Selection and 'Mother Tongues': A Neglected Component in Language Evolution. Em D. Oller \& U. Griebel (Orgs.), The Evolution of Communication System: A Comparative Approach .(pp.275-296). Cambridge: MIT Press.

Fitch, T. \& Giedd, J. (1999). Morphology and Development of the Human Vocal Tract: a Study Using Magnetic Resonance Imaging. Journal of the Acoustical Society of America, 106(3), 1511-1522.

Foley, R. (1996). An Evolutionary and Chronological Framework for Human Social Behaviour. Em W. Runciman, J. Maynard Smith \& R. Dunbar (Orgs.), Evolution of Social Behaviour Patterns in Primates and Man (pp.95-117). Oxford University Press.

Gallup, G. \& Burch, R. (2004). Semen Displacement as a Sperm Competition in Humans. Evolutionary Psychology, 2, 12-23.

Gould, S.J. \& Vrba, E. (1982). Exaptation - A Missing Term in the Science of Form. Paleobiology, 8, 14-15.

Grafen, A. (1990). .Biological Signals as Handicaps. Journal of Theoretical Biology, 144, 475-546.

Grafen, A. (1992). Modelling in Behavioural Ecology. Em J. Krebs \& N. Davies (Orgs.), Behavioural Ecology (pp. 5-31). Blackwell Scientific

Haig, D. (1993). Genetic Conflicts in Human Pregnancy. Quarterly Review of Biology, 68, 495-532.

Halliday, T. (1983). The Study of Mate Choice. Em P. Bateson (Org.), Mate Choice (pp. 3-32). Cambridge: University Press.

Hamilton, W. (1964). The Genetical Evolution of Social Behavior. Journal of Theoretical Biology, 7, 1-52.

Harvey, P. \& Bradbury, J. (1993). Sexual Selection. Em J. Krebs \& N. Davies (Orgs.), Behavioural Ecology: An Evolutionary Approach (pp.203-233). Boston: Blackwell Scientific.

Hawkes, K., J. O'Connell, N. Blurton Jones, H. Alvarez \& Charnov, E. (1998). Grandmothering, Menopause and the Evolution of Human Life Histories. Proceedings of the National Academy of Sciences, 95, 1336-1339.
Hill, S. \& Reeve, H. (2004). Mating Games: the Evolution of Human Mating Transactions. Behavioral Ecology, 15, 748-756.

Hinton, G. \& Nowlan, S. (1987). How Learning Can Guide Evolution. Complex Systems, 1, 495-502.

Hollien, H., R. Green \& K. Massey (1994). Longitudinal Research on Adolescent Voice Change in Males. Journal of the Acoustical Society of America, 96, 646-654.

Houde, A. (2001). Sex Roles, Ornaments and Evolutionary Explanation. Proceedings of the National Academy of Sciences, 98(23), 12.857-12.859.

Hrdy, S. B. (1981). The Woman that Never Evolved. Harvard: University Press.

Hughes, S., Harrison, M. \& G. Gallup,Jr. (2002). The Sound of Symmetry: Voice as a Marker of Developmental Instability. Evolution and Human Behavior, 23, 173-180.

Kacelnik, A. \& Norris, S. (1998). Signalling via Testosterone: Communicating Health and Vigour. Behavioral and Brain Sciences, 21(3), 378.

Kaplan, H. \& Hill, K. (1985). Hunting Ability and Reproductive Success Among Male Ache Foragers. Current Anthropology, 26, 131-133.

Kenrick, D. \& Keefe, R. (1992). Age Preferences in Mates Reflects Sex Differences in Reproductive Strategies. Behavioral and Brains Sciences, 15, 75-133.

Kimura, D. (1999). Sex and Cognition. Cambridge: MIT Press.

Kirkpatrick, M. (1982). Sexual Selection and the Evolution of Female Choice. Evolution, 36, 1-12.

Komarova, N. \& Nowak, M. (2001). Natural Selection of the Critical Period for Language Acquisition. Proceedings of the Royal Society B: Biological Sciences, 268, 1189-1196.

Kukla, A. (2001). Methods of Theoretical Psychology. Cambridge: MIT Press.

Lieberman, P. (1984). The Biology and Evolution of Language. Harvard: University Press.

Lieberman, P. \& Crelin, E. (1971). On the Speech of Neanderthal Man Linguistic Inquiry, 2, 203-222.

Maki, P., Zonderman, A. \& Resnick, S. (2001). Enhanced Verbal Memory in Nondemented Elderly Women Receiving Hormone Replacing Therapy. American Journal of Psychiatry, 158(2), 227-233.

Marlowe, F. (2005). Hunter-Gatherers and Human Evolution. Evolutionary Anthropology, 14(2), 54-67.

Maynard Smith, J. \& Brown, R. (1986). Competition and Body Size. Theoretical Population Biology, 30, 166-179.

Mayr, E. (1961). Cause and Effect in Biology. Science, 134, 1501-1506.

Mayr, E. (1997). The Objects of Selection. Proceedings of the National Academy of Sciences, 94, 2091-2094.

McHenry, H. (1994). Tempo and Mode in Human Evolution. Proceedings of the National Academy of Sciences, 91, 67806786.

McHenry, H. \& Coffing, C. (2000). Australopithecus to Homo: Transformations in Body and Mind. Annual Review of Anthropology, 29, 125-166.

Miller, G. (1998). How Mate Choice Shaped Human Nature: A Review of Sexual Selection and Human Evolution. Em C. Crawford \& D. Krebs (Orgs.), Handbook of Evolutionary Psychology: Ideas, Issues and Applications (pp.87-129). Mahwah: Lawrence Erlbaum.

Miller, G. (2002). How Did Language Evolve? Em H. Swain (Org.), Big Questions in Science (pp.79-99). London: Jonathan Cape. 
Miller, G. \& Todd, P. (1995). The Role of Mate Choice in Biocomputation: Sexual Selection as a Process of Search, Optimization and Diversification. Em W. Banzaf \& F. Eckman (Orgs.), Evolution and Biocomputation: Computational Models of Evolution (pp.169-204). Springer-Verlag.

Nesse, R. \& Williams, G. (1996). Why We Get Sick: The New Science of Darwinian Medicine. New York: Vintage Books.

Newmeyer,F. (1998). On the Supposed 'Counterfuncionality' of Universal Grammar: Some Evolutionary Considerations. Em Hurford, J., M. Studdert-Kennedy \& C. Knight (Orgs.), Approaches to the Evolution of Language (pp. 305-319). Cambridge: University Press.

O`Donald, P. (1978). Rare Male Mating Advantage. Nature, 272, 189.

O`Donald, P. (1980). Genetic Models of Sexual Selection. Cambridge: University Press.

O`Donald, P. (1983). Sexual Selection by Female Choice. Em P. Bateson (Org.), Mate Choice (pp. 53-66). Cambridge: University Press.

Ohala, J. (1984). An Ethological Perspective on Common CrossLanguage Utilization of F0 of Voice. Phonetica, 41, 1-16.

Ohala, J. (2000). The Irrelevance of the Lowered Larynx in Modern Man for the Evolution of Speech. EvoLang: Evolution of Language Conference (2000). (pp.171-172). ENST, Paris.

Okanoya, K. (2002) Sexual Display as a Syntactic Vehicle: the Evolution of Syntax in Birdsong and Human Language Through Sexual Selection Em A. Wray (Org.), The Transition to Language (pp. 46-64). Oxford University Press.

Okanoya, K. (2004). Functional and Structural Pre-Adaptations to Language: Insight from the Comparative Cognitive Science into the Study of Language Origin. Japanese Psychological Research 46(3), 207-215.

Phillips, C., Kazanina, N. \& Abada, S. (2005). ERP Effects of the Processing of Syntactic Long-Distance Dependencies. Cognitive Brain Research, 22, 407-428.

Pinker, S. (1994). The Language Instinct. London: Penguin Books.

Pinker, S. \& Bloom, P. (1990). Natural Language and Natural Selection. Behavioral and Brain Sciences, 13, 707-784.

Popper, K. (1959). The Logic of Scientific Discovery. London: Hutchinson.

Puts, D., Gaulin, S. \& Verdolini, K. (2006). Dominance and the Evolution of Sexual Dimorphism in Human Voice Pitch. Evolution and Human Behavior, 27, 283-296.

Quartz, S. \& Sejnowski, T. (1997). The Neural Basis of Development: A Constructivist Manifesto. Behavioral and Brain Sciences, 20, 537-596.

Riede, T. \& Fitch, T. (1999). Vocal Tract Length and Acoustics of Vocalization in the Domestic Dog (Canis familiaris). The Journal of Experimental Biology, 202, 2859-2867.

van Schaik, C. (1982). Why are Diurnal Primates Living in Groups? Behaviour, 87, 120-144.

Simmons, L. \& Emlen, D. (2006). Evolutionary Trade-Off between Weapons and Testes. Proceedings of the National Academy of Sciences, 103(44), 16346-16351.
Sloman, A., Chrisley, R. \& Scheutz, M. (2005). The Architectural Basis of Affective States and Processes. Em J.-M. Fellous \& M. Arbib (Orgs.), Who Needs Emotions?: The Brain Meets the Machine (pp.203-244). Oxford: University Press.

Smith, E. A. (2004). Why do Good Hunters Have Higher Reproductive Success? Human Nature 15(4), 342-363.

Stevens, K. (1972). Quantal Nature of Speech. Em E. David Jr. \& P. Denis (Orgs.), Human Communication: An Unified View (pp.51-66). New York: McGraw-Hill.

Stromswold, K. (2001). The Heritability of Language: A Review and Metaanalysis of Twin, Adoption and Linkage Studies. Language, 77, 647-723.

Symons, D. (1979). The Evolution of Human Sexuality. Oxford: University Press.

Thornhill, R. (1986). Relative Parental Contribution of the Sexes to their Offspring and the Operation of Sexual Selection. Em M. Nitecki \& J. Mitchell (Orgs.), Evolution of Animal Behavior: Paleontological and Field Approaches (pp.113-136). Oxford: University Press.

Tooby, J. \& Cosmides, L. (1990). The Past Explains the Present: Emotional Adaptations and the Structure of Ancestral Environments. Ethology and Sociobiology, 11, 375-424.

Trivers, R. (1972). Parental Investment and Sexual Selection. Em B. Campbell (Org.), Sexual Selection and the Descent of Man 1871-1971 (pp.136-179). Los Angeles: Aldine Press.

Trivers, R. (1974). Parent-Offspring Conflict. American Zoologist, 14, 249-264.

Uriagereka, J. (2000). Algumas Notas sobre Economia dentro da Lingüística. DELTA, 16, 221-243.

van Dommelen, W. \& Moxness, B. (1995). Acoustic Parameters in Speaker Height and Weight Identification: Sex-Specific Behaviour. Language and Speech, 38(3), 267-287.

Waddington, C. (1942). Canalization of Development and the Inheritance of Acquired Characters. Nature, 150, 563-565.

Wadnerkar, M., Cowell, P. \& Whiteside, S. (2006). Speech Across the Menstrual Cycle: a Replication and Extension Study. Neuroscience Letters, 408, 21-24.

Williams, G. (1966). Adaptation and Natural Selection. Princeton: University Press.

Wilson, E. O. (1975). Sociobiology. Harvard University Press.

Yamauchi, H. (2004). Baldwinian Accounts of Language Evolution. Tese de Doutorado, University of Edinburgh, Edinburgh.

Zahavi, A. (1975). Mate Selection - A Selection for a Handicap. Journal of Theoretical Biology, 53, 205-214.

Recebido em 07.03.2007

Primeira decisão editorial em 27.06.2007

Versão final em 02.08.2007

Aceito em 24.10.2007 